\title{
Domestic Hygiene Practices and Factors that Risks for Childhood Diarrhoea Among Under Five Children in Isolated Chars of Gaibandha, Bangladesh
}

\author{
*MB Hossain ${ }^{1}$, A Lutfa ${ }^{2}$, AMAA Awwal ${ }^{3}$
}

\begin{abstract}
Background: Worldwide diarrheal disease is the second leading cause of death in under-five years children. In Bangladesh diarrhoea kills half million under-five children every year second to pneumonia. The study was aimed to assess the domestic hygiene practices and find the factors that risked for diarrheal disease in under-five children among the families that resides in isolated chars of Gaibandha district.
\end{abstract}

Method: A community based cross-sectional study design was employed in 2011 at three unions of Gaibandha district. Random sampling technique was employed to select 322 households that had at least one under-five children. Data was collected using pretested structured questionnaire.

Result: A total of 322 children were enrolled. The overall diarrhoea prevalence was $20.8 \%$. About $71 \%$ $(n=255)$ of households collected drinking water from improved water sources and only $10.8 \%(n=17)$ had been using river water for their cooking. We found a lower prevalence of diarrhoea in children whose mother had a higher education level. More than $60 \%$ mothers didn't wash their hands before feeding their children. A good scenario has been observed that babies were breastfed for sufficient time period. Apart from diarrhoea, Otitis media and skin diseases were significantly found in chars babies. About $20 \%$ of the babies were found not immunized and $43.2 \%$ found immunized and over $40 \%$ partially immunized. Half of the families were found deprived from primary health care facilities and there were found only one satellite clinic in the study sites.

Conclusion: The level of diarrheal disease variation was varied due to maternal education, socio-economic status, personal hygiene, waste disposal system and public awareness. Thus enhancing community based behavioural change communication that emphasize on personal hygiene and sanitation should be strengthening to reduce childhood diarrhoea.

Key Words: Childhood diarrhoea, house hold, isolated chars, Brahmaputra

\section{Introduction}

Diarrhoeal diseases are the second leading cause of death in children aged under 5 years worldwide. ${ }^{1}$ An estimated 2.5 million cases of diarrhoea occur annually in these children, with Asia and southern Africa accounting for more than half. ${ }^{2}$ Three quarters of global childhood diarrheal deaths occur within only 15 countries and Bangladesh is in $7^{\text {th }}$ position with 50,800 annual childhood deaths. ${ }^{3}$
In Bangladesh, a rural child, on average suffers from 4.6 episodes of diarrhoea every year while 230,000 children die due to the disease. ${ }^{4}$ The infectious agents associated with diarrhoeal disease are transmitted mainly through the faecal-oral route. ${ }^{1}$ In developing countries, diarrhoeal infections under 5 years child are generally associated with rotavirus. ${ }^{5}$ Diarrheal diseases can be

$1 *$ Dr. Muhammad Belal Hossain, Department of public health, American International University-Bangladesh

${ }^{2}$ Dr. Lutfa Akther, Program co-ordinator (Training), RHSTEP, Dhaka Medical College Hospital, Dhaka

${ }^{3}$ Dr. A. A. M. Anisul Awwal, Director, (Training), National Institute of Population Research and Training, Bangladesh

*Corresponding Author

Date of submission: 26.01.2017 Date of acceptance: 20.07.2018

AKMMC J 2019; 10(1) : 05-10 
attributed to contaminated drinking water, poor sanitation and hygiene, and more broadly to poverty. ${ }^{6}$ Ingestion of contaminated water, inadequate availability of water for hygiene, and lack of access to sanitation contribute to about 1.5 million child deaths and around $88 \%$ of deaths from diarrhea per year. ${ }^{7}$

Over the last few decades, remarkable improvements have been made in understanding the epidemiology, ecology, interventions, and prevention methods of diarrhoeal diseases. However, the incidence of diarrhoea appears to have remained stable globally. ${ }^{8}$ The inhabitants of island of Brahmaputra had been suffering from massive natural disasters like river erosion, flood, and diseases epidemics. Little is known about their health care status thus the present study was conducted to assess their domestic hygiene status and childhood diarrhoea prevalence.

\section{Methods}

The study was conducted in three unions namely Kamarjani, Erendabari and Mollarchar of two upazila (Gaibandha sadar and Fulchari) of Gaibandha district using random sampling technique. The study carried out in the rural communities of isolated islands of the river Brahmaputra, a trans-boundary river and one of the major rivers of Asia. The study was cross sectional in nature during the period of January to June of 2011, among nine village communities participated in different NGO activities. Participants were selected who had no land more than 3 decimals, no permanent house and had at least one river erosion experience. 322 participants were included in the study whom was asked for an in-depth interview with a pretested questionnaire. The respondents were consented before interviewing. Data were analyzed using SPSS for Windows version 15.2 (SPSS Inc., USA).

\section{Results}

Table 1: General characteristics of enrolled households

\begin{tabular}{lc}
\hline Characteristics & $\mathbf{n}(\%)$ \\
\hline Weight at birth & $96(29.8)$ \\
$<2.5 \mathrm{Kg}$ & $188(58.3)$ \\
$2.5-3.5 \mathrm{Kg}$ & $38(11.8)$ \\
Don't know & \\
Sex & $170(52.8)$ \\
Male & $152(47.2)$ \\
Female & \\
Occupation of mothers & $302(93.8)$ \\
Housewife & $10(3.1)$ \\
Services (maid servant) & $10(3.1)$ \\
Others & \\
Education level of mothers & \\
No schooling & $70(21.7)$ \\
Primary school & $172(53.4)$ \\
Secondary school & $70(21.7)$ \\
Higher secondary and above & $10(3.1)$ \\
Occupation of fathers & \\
Farmer & $20(6.2)$ \\
Day labour & $20(6.2)$ \\
Fisherman & $20(6.2)$ \\
Service & $10(3.1)$ \\
Boatman & \\
Others & \\
\hline
\end{tabular}

Table 1 describes that, about $30 \%$ children had weight less than 2.5 Kilograms at their birth, 58\% had 2.5-3.5 kilogram and $12 \%$ respondents didn't know the birth weight of their children. Among the surveyed households $21 \%$ mothers of enrolled children had no schooling; half of the mothers had attended primary school and quarter of mothers passed primary level of education. Almost half of the fathers of children were farmer, quarter of them was day labour, $16 \%$ fisherman, $6 \%$ boatman, and rest were involved with other business. 
Table 2: Socio-economic status of enrolled households

\begin{tabular}{lc}
\hline Characteristics & n (\%) \\
\hline Monthly family income of the household & \\
$<5000$ BDT (60 USD) & $132(41)$ \\
$5000-10000$ BDT (60-125USD) & $170(52.8)$ \\
$>10000$ (125USD) & $20(6.2)$ \\
Floor type of households & \\
Sand & $282(87.6)$ \\
Mud & $40(12.4)$ \\
Water sources for cooking & \\
River water & $35(10.8)$ \\
Tube well water & $229(71.1)$ \\
Mixed (Partially from both) & $58(18)$ \\
Hand washing practices before feeding of child \\
Yes & $120(37)$ \\
No & $202(62.7)$ \\
Duration of breast feeding & \\
$<6$ Months & \\
6-12 Months & $36(11.2)$ \\
$>12$ Months & $190(59)$ \\
Type of latrine using in households & $96(29.8)$ \\
Traditional & \\
Sanitary & \\
Handwashing practices after defecation & \\
Soap & \\
Soil & \\
Ash & \\
Nothing & \\
\hline
\end{tabular}

Table 2 depicts that, Over $40 \%$ of the families living in isolated chars of Brahmaputra were living under poverty margin, which is higher than national poverty rate of $26 \%$. More than half of the households' monthly income ranges 5000-1000 Taka (60-125 USD). It was found that almost every households' floor were consists of sand and only $12 \%$ of them were by soil. There were no cemented house had been observed. Majority $(71 \%)$ of the families used tube well water for their cooking purpose and $10 \%$ respondents' families used river water and $18 \%$ families used both sources. About $40 \%$ respondent households used to use sanitary latrine and $55 \%$ were using traditional pit latrine or practiced open defecation. Hand washing practices after defecation was observed quite well among the respondents, $62 \%$ used soap, $8 \%$ used soil, $2 \%$ used ash and $27 \%$ of respondents used nothing. We found, $11 \%$ babies were breastfed less than six months of their age, 59\% children had breastfed up to twelve months and rest were fed more than one year.

Table 3: Prevalence of diarrhoea and clinical information of enrolled children

\begin{tabular}{lc}
\hline Characteristics & $\mathbf{n}(\%)$ \\
\hline $\begin{array}{l}\text { Occurrence of diarrhoea (in past four } \\
\text { week of interview) }\end{array}$ & \\
Yes & $67(20.8)$ \\
No & $255(79.2)$ \\
Types of diarrhoea & \\
Simple watery & $242(75.2)$ \\
Mucoid & $80(24.8)$ \\
History of measles & \\
Yes & $20(6.2)$ \\
No & $302(93.8)$ \\
History of chronic diseases & \\
Yes & $44(13.7)$ \\
No & $278(86.3)$ \\
Vitamin A intake & \\
Yes & $196(61.4)$ \\
No & $78(24.2)$ \\
Don't know & $48(14.9)$ \\
Immunization status of children & \\
Immunized (all vaccines) & $139(43.2)$ \\
Not immunized & $64(19.9)$ \\
Partially immunized & $119(40)$ \\
\hline
\end{tabular}

In table 3, we observe that prevalence of diarrhoea among under five children was $21 \%$ past three weeks of interview of respondent mothers. Three quarter of the diarrhoea was simple watery in nature and $25 \%$ was Mucoid type. More than $90 \%$ children had no history of Measles but majority of children have had chronic diseases since their birth like respiratory distress and hydrocele. Over $80 \%$ children had taken Vitamin A capsule and 9.3\% mothers did not know whether their children taken or not. $43 \%$ children were found immunized, $20 \%$ were not and $40 \%$ had not been completed all vaccines of expanded programmed on immunization. 
Table 4: Management of diarrhoea and provision of primary health care facilities

\begin{tabular}{lc}
\hline Characteristics & n (\%) \\
\hline \multicolumn{2}{l}{ Knowledge on ORS making in home condition } \\
Yes & $60(18.6)$ \\
No & $132(41)$ \\
Not fully & $130(40.4)$ \\
Management practices of diarrhoea & \\
Homemade ORS & $20(6.2)$ \\
Manufactured ORS & $252(78.3)$ \\
Green Coconut juice & $20(6.2)$ \\
Other foods & $30(9.3)$ \\
Zinc supplementation during diarrhoea & \\
Yes & $70(21.7)$ \\
No & $252(78.3)$ \\
Distance from primary health care centre & \\
0-2 KM & $90(27.9)$ \\
2-4 KM & $182(56.5)$ \\
$>4$ KM & $50(15.5)$ \\
Type of health care providers & \\
Traditional healer (Kobiraj) & $20(6.2)$ \\
Government health worker & $20(6.2)$ \\
Drug sellers & $60(18.6)$ \\
Family planning worker & \\
NGO staff & \\
Paramedics & \\
\hline & \\
& \\
& \\
&
\end{tabular}

Table 4 describes, about $19 \%$ respondent mothers knew how to make oral rehydration saline, $41 \%$ did not know and $40 \%$ knew the process part. In the present study, it was observed that $78 \%$ cases of childhood diarrhoea was managed by commercially manufactured ORS, some used green coconut juice, homemade ORS and $9.3 \%$ feed other foods in response to diarrhoea. Zinc was not found significantly supplemented in chars area; only $22 \%$ mothers supplemented zinc during the onset of diarrhoea to their children.

Facilities of primary health care were found very poor in the study area, where only $28 \%$ families had the access to PHC within two kilometers of distance. Half of the households had very less scope to get PHC facilities and $16 \%$ families were found very vulnerable in terms of health emergency. There were no graduate physician in chars area and quarter of respondent families relies on traditional healer. NGO health care staffs provided health care support in $37 \%$, cases followed by drug sellers $18.6 \%$, family planning worker $6.8 \%$, and Paramedics $6.2 \%$ respectively.

\section{Discussion}

An overwhelming majority of the people in island are extremely poor. This rate is exceedingly high compared to the national average. It is evident from the comparative rates that the prevalence of poverty is more than double in island compared to mainland. Lower socioeconomic status and lack of breastfeeding are key correlates of increased risk for cholera hospitalization among those under five in rural and urban Bangladesh ${ }^{9}$ and similar things found in another study conducted in Ethiopia. ${ }^{10}$

It was observed that diarrhoea prevalence was high in those babies whose maternal education was low. This finding supports Mahalanabis et al. study ${ }^{11}$ and a similar study in Iraq ${ }^{12}$, Vietnam ${ }^{13}$ where the risk of diarrhoea was three times higher among children with fathers who had lower level of education. However, the findings contrary to an Ugandan study where investigators found diarrhoea was more likely to happen among those children of mothers with a secondary level of education. ${ }^{14}$ A significant number of the study households did not use the sanitary latrines $(25 \%)$ whereas $75 \%$ of had used sanitary latrines that agrees the study in Kustia ${ }^{15}$ where $36 \%$ of study households had kaccha and $58.75 \%$ had sanitary latrines and $5.25 \%$ used others. It was mentioned in a study in Vietnam that diarrhea could be prevented in about $20 \%$ of the children by having access to hygienic latrines in the households. ${ }^{13}$

In the present study, $11 \%$ of the households had been using river water for cooking and $71 \%$ tube well water. Usually mother feed their children with their own hand but they don't use soap for washing their hand. 37\% mothers washed their hands before feeding their children and $63 \%$ did not. Knowledge on drinking safe water was quite low in chars peoples. More than quarter of dwellers didn't use soap for washing their hands before eating, similar findings was observed in a study of Ethiopia. ${ }^{16}$

Around 44 percent chars peoples had been using traditional pit toilet, 56 percent had used sanitary toilet with the help of different NGOs. Practice of washing hands after defecation was found quite 
better, about 62 percent peoples used soap and maintained a considerable hygiene practices, 7.8 percent used soil, 2.2 percent used ash and 27.3 percent respondents didn't practice anything after defecation.

The overall prevalence of diarrhoea among under five children was found $20.8 \%$ which is similar to an study conducted in Kustia 15 In a study in Uganda, researchers found age was significantly associated with rotavirus and mostly occurred those whose age were less than 24 months. ${ }^{14}$ and same thing was found in eastern Ethiopia. ${ }^{17}$ Prevalence of diarrhoeal episodes seemed higher as those areas were prone to be flooded during monsoon. Natural disasters such as flooding have been shown to increase the risk of diarrheal disease. ${ }^{18}$ In diarrhoeal events, $75.2 \%$ episodes were simply watery, $24.8 \%$ were mucoid in type which can play a significant role for stunting the growth of babies found in a similar study. ${ }^{19}$

Almost every mothers practice breast feeding to their children, they offered only cow milk additional to breast feeding. This findings agree with another study in Bangladesh, where investigation found over $80 \%$ babies consumed breast milk. ${ }^{20}$ In a hospital based surveillance in rural and urban Bangladesh, investigators found, breastfeeding halved the risk in both rural settings. ${ }^{9}$ Only $6 \%$ children experienced measles and 28 percent children found suffered from chronic diseases. About $78 \%$ mothers fed manufactured oral rehydration saline which was satisfactory and better scenario in comparison to other study where many rural families find hard to afford ORS packets ${ }^{21}$ and better than the study conducted in India where found $12.7 \%$ children fed ORS in response to diarrhoea. ${ }^{22}$ Zinc plays a vital role in controlling diarrhea but in chars condition babies were not found to have had zinc during diarrhea, only 21.7 percent children supplemented zinc during diarhoeal episodes. In chars area, $61 \%$ babies had vitamin A supplementation and $43 \%$ percent babies were found immunized regarding their age which is less than national EPI coverage, $20 \%$ babies grown up without having all the vaccines and $40 \%$ were found not immunized. In chars area, there had no graduate physician. Traditional healers were found prominent among health care providers, drug sellers and different development workers mainly treated the inhabitants.

\section{Limitations}

We relied on the history given by the respondent mother at the time of their home visit. So, the occurrences of diarrhoea, type of diarrhoea, and ORS use and other information solely depend on their conversation. Regardless this, the study had a small sample size which may not be representative picture for the total population in chars area.

\section{Conclusion}

It has been clearly evident that there is an urgent need for special attention to the health services for the inhabitants of island chars especially for children. Our health policy applicable for the whole country may not work for vulnerable areas like islands. Therefore, special health policy needs to be designed for islands in the national health policy.. Provision of basic water and sanitation services across the whole chars area, have to ensure safe drinking water and educate them to use safe water and its valuable importance. Change behaviors through community involvement, education and health-promotion activities. A pregnancy allowance can be provisioned for island char mothers most of whom cannot afford sufficient and quality reproductive health care due to poverty. To address the scarcity of qualified medical professionals in island chars, local young people having some minimum level of education can be trained as rural medical practitioners. The local administration (health authorities working at the upazila level) has to ensure that the services supposed to be provided to any citizen of the country reach the island char dwellers.

\section{Acknowledgement}

The authors would like to extend thanks to Dr. Monowara Begum, District livelihood co-coordinator, Gaibandha, Chars Livelihood Programme and Prof. Neaz Ahmed, AIUB for their invaluable support and guidance to accomplish the study.

Conflict of interest: We have no conflict of interest.

\section{References}

1. Thomas JC WD. Epidemiologic methods for the study of infectious disease. Oxford University Press 2001.

2. You D, Jones G, Hill K, et al. Levels and trends in child mortality, 1990-2009. The Lancet 2010; 376(9745): 931-3. 
3. Boschi-Pinto C, Velebit L, Shibuya K. Estimating child mortality due to diarrhoea in developing countries. Bulletin of the World Health Organization 2008; 86(9): 710-7.

4. Baqui AH, Black RE, Sack RB, et al. Epidemiological and clinical characteristics of acute and persistent diarrhoea in rural Bangladeshi children. Acta paediatrica 1992; 81(s383): 15-21.

5. D. Rogers JM, R. Beaglehole and H. Tanaka. The practice of public health. Oxford text book of Public Health 2002.

6. Zwane AP KM. What works in fighting diarrheal diseases in developing countries? A critical review. World Bank Res Observ 2007.

7. JJ G. reducing risks, promoting healthy life. The world health report 2002.

8. Kosek M, Bern C, Guerrant RL. The global burden of diarrhoeal disease, as estimated from studies published between 1992 and 2000. Bulletin of the World Health Organization 2003; 81(3): 197-204.

9. Colombara DV, Cowgill KD, Faruque AS. Risk factors for severe cholera among children under five in rural and urban Bangladesh, 2000-2008: a hospital-based surveillance study. PloS one 2013; 8(1): e54395.

10. Nahar B, Ahmed T, Brown KH, Hossain MI. Risk factors associated with severe underweight among young children reporting to a diarrhoea treatment facility in Bangladesh. Journal of health, population, and nutrition 2010; 28(5): 476.

11. Mahalanabis D, Faruque AS, Islam A, et al. Maternal education and family income as determinants of severe disease following acute diarrhoea in children: a case control study. Journal of biosocial science 1996; 28(02): 129-39.

12. Alaa H, Shah SA, Khan AR. Prevalence of diarrhoea and its associated factors in children under five years of age in Baghdad, Iraq. Open Journal of Preventive Medicine 2014; 2014.

13. Vu Nguyen $\mathrm{T}$, Le Van $\mathrm{P}$, Le Huy $\mathrm{C}$, et al. Etiology and epidemiology of diarrhea in children in Hanoi, Vietnam. International Journal of Infectious Diseases 2006; 10(4): 298-308.
14. Nakawesi JS, Wobudeya E, Ndeezi G, et al. Prevalence and factors associated with rotavirus infection among children admitted with acute diarrhea in Uganda. BMC pediatrics 2010; 10(1): 69 .

15. Khatun A, Rahman SS, Rahman $\mathrm{H}$, et al. A cross sectional study on prevalence of diarrhoeal disease and nutritional status among children under 5-years of age in Kushtia, Bangladesh. Science 2013; 1(2): 56-61.

16. Gebru T, Taha M, Kassahun W. Risk factors of diarrhoeal disease in under-five children among health extension model and non-model families in Sheko district rural community, Southwest Ethiopia: comparative cross-sectional study. BMC public health 2014; 14(1): 395.

17. Mengistie B, Berhane Y, Worku A. Prevalence of diarrhea and associated risk factors among children under-five years of age in Eastern Ethiopia: A cross-sectional study. Open Journal of Preventive Medicine 2013; 3(07): 446.

18. Ivers LC, Ryan ET. Infectious diseases of severe weather-related and flood-related natural disasters. Current Opinion in Infectious Diseases 2006; 19(5): 408-14.

19. Alam DS, Marks GC, Baqui AH, et al. Association between clinical type of diarrhoea and growth of children under 5 years in rural Bangladesh. International journal of epidemiology 2000; 29(5): 916-21.

20. Black R, Huq I, Merson M, et al. Incidence and severity of rotavirus and Escherichia coli diarrhoea in rural Bangladesh: implications for vaccine development. The Lancet 1981; 317(8212): 141-3.

21. Ali M, Atkinson D, Underwood P. Determinants of use rate of oral rehydration therapy for management of childhood diarrhoea in rural Bangladesh. Journal of Health, Population and Nutrition 2000: 103-8.

22. Sudarshan M, Parasuramalu B. An epidemiological survey of diarrhoea among children in the Karnataka region of kaveri basin. Indian Journal of Community Medicine 1995; 20(2): 41. 